\title{
Las políticas públicas de equidad de género Tecnologías de género moderno colonial
}

\section{Las políticas públicas de equidad de género Tecnologías de género moderno colonial}

\section{Celenis Rodríguez Moreno}

$E_{n}$ este trabajo se analiza el discurso de las políticas públicas de mujer y género desde una perspectiva feminista descolonial, mediante el rastreo de ideas y significados raciales y coloniales contenidos en sus categorías. Esto permitiría observarlas como tecnologías que ordenan las relaciones de género, clase y raza y reinstalan las y los estereotipos sexistas, racistas y clasistas que atraviesan a las sociedades con un pasado colonial. Además, dichas políticas públicas sirven de vehículo para la instalación de nuevas gramáticas racistas y la actualización de la norma de género moderno colonial.

Palabras clave: políticas públicas de mujer y género, sistema de género moderno/colonial, mujeres, tecnologías de género moderno/colonial, mímesis.

This paper aims to carry out an analysis of the discourse of public policies on women and gender from a decolonial feminist perspective by tracing ideas and racial meanings contained in their categories of analysis. This would allow observing them as technologies that order gender, class and race relations that run through societies with a colonial past. In addition, these public policies serve as a vehicle for the installation of new racist grammars and the updating of the modern colonial gender norm.

Key words: public policies on women and gender, modern/colonial gender system, women, modern/colonial gender technologies, mimicry.

Fecha de recepción: 19 de julio de 2021

Fecha de dictamen: 20 de julio de 2021

Fecha de aprobación: 1 de septiembre de 2021 


\section{INTRODUCCIÓN}

Este ensayo propone una reflexión de las políticas públicas de mujer y género desde un abordaje feminista descolonial. Se centra en un análisis epistémico de las categorías que utilizan dichas políticas públicas para diagnosticar y prescribir medidas que buscan solucionar el problema de desigualdad entre varones y mujeres. Metodológicamente, es un ejercicio de análisis del discurso de tipo foucaultiano, por lo tanto, las políticas públicas son tratadas como relatos, producidos por los Estados, que instalan representaciones de mundo, marcos de inteligibilidad (Muller, 2006). Pero también cumplen una función subjetivadora ya que a partir de la mirada de mundo que ofrecen y performan gestionan el deseo, los espacios, el tiempo, regulando la experiencia posible de su sujeto, de ahí que se retome la tesis de Teresa de Lauretis y se proponga entenderlas como tecnologías de género. Una vez relevados los elementos discursivos que permiten observarla como tecnología de género, se examinarán con las herramientas teóricas del feminismo descolonial y poscolonial y la teoría descolonial en la búsqueda de ideas y significados raciales de origen colonial que, según la pensadora descolonial María Lugones, son co-constitutivos de la norma de género, lo que además dejaría entrever el papel de las políticas públicas de género como tecnologías de género moderno colonial que reinstalan la norma de género. Para realizar este trabajo de análisis se toman como referencia tres políticas públicas nacionales de Colombia que se diseñaron y pusieron en marcha durante la década de 1990.

\section{TECNOLOGÍAS DE GÉNERO MODERNO/COLONIAL}

Las políticas públicas de equidad de género, también conocidas como políticas públicas de mujer y género, son para una gran parte del feminismo institucionalizado que opera al interior del Estado en ministerios, direcciones u oficinas de la mujer, y para algunos sectores del movimiento feminista y social de mujeres, la estrategia más efectiva para transformar las desiguales relaciones de género entre varones y mujeres. Sin embargo, a pesar del ideal aparentemente transgresor que las sustenta, terminan reproduciendo el orden sexo-genérico, funcionando como tecnologías de género. ${ }^{1}$

\footnotetext{
1 "Las tecnologías de género, por tanto, estarían ligadas con prácticas socioculturales, discursos e instituciones capaces de crear 'efectos de significado' en la producción de sujetos hombres y sujetos mujeres. En conclusión, el género y las diferencias sexuales serían efecto de representaciones y prácticas discursivas" (Moreno, 2011:49).
} 
Un primer paso para comprender esta afirmación es señalar qué se entiende por políticas públicas de mujer y género y qué se entiende por tecnología de género. En este trabajo las políticas públicas se asumen desde un enfoque cognitivo que las define como constructoras de mundo; productoras de visiones del mundo. Las políticas, como sostiene Pierre Muller (2006), son portadoras de una idea específica y distintiva de un problema; de una representación de un grupo social, y de una "teoría del cambio social". Las políticas públicas contribuyen, entonces, por un lado, a la configuración de un "espacio de sentido" (público, desde luego) que proporciona un mundo-visión y, por el otro actúan, en últimas, a la manera de un "sistema de creencias" que guía las conductas públicas (Puello, 2007). En este orden de ideas, una política pública de equidad de género produciría una visión sobre lo que significa ser una mujer; una idea de mundo organizado según las diferencias sexuales; y una representación del lugar de las mujeres en el mundo, de sus intereses y de sus deseos mientras plantea el "problema mujer" sobre el cual el Estado prescribirá una serie de medidas.

Por otra parte, la idea de tecnología de género de la feminista italiana Teresa de Lauretis (2000:35), sostiene que "el género es el conjunto de los efectos producidos en los cuerpos, comportamientos y relaciones sociales debido al despliegue de una serie de tecnologías sociales, de aparatos tecno sociales o bio-médicos". Esto significa que, pensar en una política pública de equidad como tecnología de género implica afirmar que ese espacio de sentido que crea, su estructura de significación, "engenerizaría" los comportamientos y las relaciones sociales de unos cuerpos con vaginas que deberían devenir sujeto mujer. En resumen, estas políticas producirían mujeres.

Para entender cómo ocurre esto es importante considerar que para autoras como Judith Butler:

El "sexo/género" es un ideal regulatorio cuya materialización se impone y se logra (o no) mediante ciertas prácticas sumamente reguladas. En otras palabras, el "sexo/género" es una construcción ideal que se materializa obligatoriamente a través del tiempo. No es una realidad simple o una condición estática de un cuerpo, sino un proceso mediante el cual las normas reguladoras materializan el sexo/género y logran tal materialización obligatoriamente en virtud de la reiteración forzada de esas normas (2002:18).

Así, la realización del ideal sexo/género aparece como un proceso altamente regulado lo que implica la intervención constante de artefactos sociales que indiquen cuáles son los roles, los espacios, los comportamientos y la manera de relacionarse de varones y mujeres. Y son, precisamente, una serie de prácticas relacionadas con estas cuestiones las que se articulan en las políticas públicas de equidad, se podría decir que de estas tareas de regulación se desprende su actuación como tecnología de género. 
Se puede observar el modo de operar de las políticas públicas como tecnologías siguiendo la estructura de significación ${ }^{2}$ que propone Pierre Muller (2006). Según este politólogo francés, la estructura de significación está compuesta por: valores, imágenes, algoritmos y normas. Por medio de los valores e imágenes se producen modos de existencia, situaciones, que ponen a las mujeres en contacto con una experiencia concreta del mundo, la cual a su vez contiene representaciones cargadas de significados positivos o negativos sobre cómo debe actuar una mujer, sobre cómo debe ser una mujer. Por su parte, los algoritmos permiten la construcción de una lógica de interpretación de esas imágenes que justifica y hace deseable la apropiación de ciertas normas/soluciones que no sólo prescriben frente a lo inmediato, sino que también regulan la posibilidad de encarnamiento del deber ser mujer. Lo que se observa, es cómo esta estructura de significación plantea un problema y argumenta la que sería la solución "lógica", la más deseable, la que podría "tomar cualquier mujer" dadas las mismas circunstancias, y es este convencimiento el que resulta clave para comprender los ejercicios de autorregulación de las mujeres frente a la norma de actuación propuesta, la ausencia de prácticas de coerción. Lo que se logra, finalmente, es crear el espejismo de la coincidencia entre las propias aspiraciones, deseos, esperanzas, decisiones, necesidades y estilos de vida con objetivos gubernamentales fijados de antemano, y además hacer que esa conducta sea vista como buena, digna, honorable y, por encima de todo, como propia, como producto de su libertad (Castro, 2010).

En este punto es necesario tener en cuenta que la estructura de significación de las políticas públicas de equidad responde a la lógica de una política de identidad, por lo que construyen tanto un relato de opresión compartida entre miembros de un colectivo social, como un sujeto arquetípico, con unos rasgos y características, muy bien delineados, estrechamente ligados a la experiencia de opresión. Así, dichas políticas producen representaciones de lo que sería una mujer y de su experiencia que refuerzan la organización de la vida social basada en la diferencia sexual, y reafirman la existencia de una sociedad dividida entre varones y mujeres, la división sexual del trabajo, la división espacio público/privado, la idea de la heterosexualidad obligatoria

${ }^{2}$ La estructura de significación de las políticas públicas articula cuatro niveles de percepción "Los valores: las representaciones más fundamentales sobre lo que es bien y lo que es mal, lo deseable o lo que está por descartar; las normas que definen las diferencias entre lo real percibido y lo real deseado. Definen unos principios de acción más que unos valores; los algoritmos son unas relaciones causales que expresan una teoría de la acción. Pueden expresarse bajo la forma de 'si... entonces'; y las imágenes (el joven agricultor dinámico y moderno) que son unos vectores implícitos de valores, de normas y aun de algoritmos. Dan significación a lo que se hace inmediatamente, sin tener que hacer largas curvas discursivas" (Muller, 2006:100). 
y los estereotipos de género. Lo que queda en evidencia es que las políticas públicas de equidad como tecnologías despliegan y articulan prácticas discursivas y no discursivas que repiten el ideal de género hasta materializarlo. Por consiguiente, estas políticas no rompen con la norma de género, sino que la reproducen incluso cuando intentan transgredirla. $\mathrm{Al}$ respecto, Teresa de Lauretis sostiene:

Paradójicamente, por tanto, la construcción del género se realiza mediante su propia deconstrucción, y también a través de cualquier discurso feminista o no, que intente rechazarlo o minimizarlo como falsa representación ideológica. Porque el género, como lo real, no es sólo el efecto de la representación, sino también su exceso, lo que permanece fuera del discurso (2000:36).

Hasta aquí se ha tratado de establecer la función de las políticas públicas de equidad como tecnologías de género, sin embargo, en el contexto de los países del Tercer Mundo y tratándose de "mujeres" negras, indígenas y pobres sería más apropiado hablar de éstas como tecnologías de género moderno colonial, ya que su función subjetivadora supondría una engenerización co-constitutiva con el orden racial.

Esta afirmación se sustenta en dos niveles de argumentación, en un primer nivel está el argumento teórico descolonial que señala que género es indisoluble de raza, como lo afirma María Lugones (2008), ya que la experiencia sociosexual que constituye la categoría mujer sólo es realizable para las mujeres blancas, quienes históricamente han participado de la distribución de espacios, roles e imaginarios basados en la diferencia sexual. Esa no ha sido la experiencia de indígenas, negras o mestizas, ${ }^{3}$ quienes desde la colonia realizan duros trabajos en el campo y en la calle, indicador de que no ha habido asignación de roles por sexo, ni imaginarios de fragilidad, y mucho menos destinación al espacio privado. Esto ocurre porque desde el periodo de la administración colonial las personas no blancas no han sido consideradas humanas sino bestias y para tener un modo de vida acorde con la norma de sexo género tenían que ser considerados humanos o humanas. Esta diferencia fundante del orden colonial persiste en los Estados nacionales que surgieron tras las luchas independentistas, los cuales adoptaron los principios republicanos de igualdad y libertad, pero sin romper con las jerarquías y privilegios que impuso la colonia.

${ }^{3}$ La mestiza que aquí menciono no es una referencia al mestizaje del proyecto nacional criollo, tampoco es una referencia a la mestiza blanqueada "exitosamente". Sino a las múltiples mezclas de los sujetos subalternizados, las mezclas impuras e imprevistas a las que se refiere Edouard Glissant (2010) en su libro El discurso caribeño. 
En un segundo nivel está el argumento de tipo funcional que muestra a las políticas públicas insertas en un dispositivo colonial como lo es el del desarrollo. Las políticas públicas de mujer y género ${ }^{4}$ que se diseñaron y pusieron en marcha en Colombia desde 1984 la "Política nacional para la mujer campesina" y hasta 2012 "Política pública nacional de equidad de género para las mujeres" y especialmente la Política integral para la mujer (1992), la Política de equidad y participación de las mujeres (1994) y el documento "Avance y ajustes de la política de participación y equidad para las mujeres" (1997) que se analizaron para este trabajo, llegaron al país como parte de los paquetes de medidas de las políticas del aparato de desarrollo. Eso explica que hayan adoptado sus metodologías -batería de indicadores, categorías de análisis, estructura textual y narrativa, así como métodos de seguimiento y evaluación- y que hayan sido diseñadas en instituciones como la Oficina Nacional de Planeación con el apoyo técnico de las agencias internacionales de cooperación para el desarrollo.

A primera vista, estas políticas públicas de mujer y género estarían dedicadas, única y exclusivamente, a equilibrar las desiguales relaciones entre varones y mujeres; no obstante, su articulación en el aparato del desarrollo refuerza la idea de que sus objetivos siempre contemplan regulaciones de raza y clase. En este sentido, es importante recordar que las tecnologías, como sostiene Foucault, no tienen usos estables, su uso suele ser estratégico, por lo que sus fines pueden ser múltiples y siempre dependen del dispositivo al cual se articulen. ${ }^{5}$ Lo que se puede deducir, siguiendo los argumentos señalados, es que las políticas públicas de equidad de género son, por donde se les mire, tecnologías de género moderno colonial, ya sea por la base conceptual de la que parten, o por ser producidas y estar engranadas a un dispositivo colonial, que ordena la vida en los

\footnotetext{
${ }^{4}$ Políticas públicas nacionales de equidad de género producidas en Colombia: "Política nacional para la mujer campesina" (1984), "Política integral para las mujeres colombianas" (1992), "Salud para las mujeres, mujeres para la salud" (1993), "Política para el desarrollo de la mujer rural" (1993), "Política de equidad y participación de las mujeres" (1994), "Avance y ajustes de la política de participación y equidad para las mujeres" (1997). Durante el primer decenio del siglo XXI se formula la política "Mujeres constructoras de paz y desarrollo" (2003) y "Política pública nacional de equidad de género para las mujeres" (2012).

5 "Los dispositivos son capaces de hacer funcionar juntas una multiplicidad de técnicas, abstrayéndolas de los objetivos particulares que tenían cuando fueron inventadas y poniéndolas a trabajar conforme a objetivos enteramente diferentes [...] Foucault dice que las técnicas de poder son 'transferibles' (Übertragbar), pues su 'uso' no se halla ligado sustancialmente a ningún objetivo en particular y tampoco depende de ninguna institución o contexto cultural. Es decir que una técnica cualquiera puede ser aislada de los objetivos que tuvo en un momento histórico determinado y puesta a funcionar en campos estratégicos que operan con objetivos diferentes" (Castro, 2010:35).
} 
países del sur global con base en jerarquías de raza y clase, como lo es el dispositivo del desarrollo.

El desarrollo es un dispositivo de saber/poder creado en los países del Norte global impuesto sobre los países del Tercer Mundo. Su línea de acción comprende en un primer momento, la aplicación de una serie de instrumentos científicos para conocer y evaluar las economías, las poblaciones, los territorios y el medio ambiente que conforman el Sur global, y en un segundo momento, la prescripción de fórmulas o recetas que en forma de planes y políticas les permitirá superar su principal problema, la pobreza (Escobar, 2007). Ahora bien, el surgimiento del desarrollo como matriz de ordenamiento geopolítico coincide con los últimos procesos de descolonización en la década de 1950 en el continente africano. Es por ello que para autores como Arturo Escobar (2007), el desarrollo no es más que un dispositivo de recolonización, de reordenamiento de poblaciones y de los centros de recursos.

En ese mismo orden de ideas, el dispositivo de desarrollo produjo un tipo de conocimiento específico sobre las mujeres, el discurso de mujer y desarrollo, el cual construyó y universalizó cierta mirada feminista occidental sobre las mujeres del Tercer Mundo, en la que la típica imagen institucional de la mujer pobre como víctima se construye con base en ideas racistas sobre ciertas culturas y sociedades.

Los textos sobre las mujeres y el desarrollo no describen, como se aduce, la situación de las mujeres del Tercer Mundo, sino la situación de su propia producción (la de los textos). La imagen resultante de las "Mujeres del Tercer Mundo" es en sí la de unas mujeres pobres, que viven en chozas, tienen demasiados hijos, son analfabetas, y dependen de un hombre para subsistir o se han empobrecido porque no lo tienen. Lo importante aquí no es si se trata de una descripción más o menos exacta de las mujeres, sino quién tiene el poder para crear la descripción y alegar que ella es, si no exacta, la mejor aproximación. El régimen discursivo de la mujer y el desarrollo no es un recuento de los intereses, las necesidades, preocupaciones y sueños de las mujeres pobres, sino un conjunto de estrategias para manejar el problema que las mujeres representan para el funcionamiento de las agencias de desarrollo del Tercer Mundo (Mueller, 1987:4).

Precisamente, una de las estrategias más visibles del discurso de mujer y desarrollo han sido las políticas públicas de mujer y género, tal y como ha sucedido en Colombia. Éstas actúan en el ámbito de la red de relaciones del dispositivo de desarrollo cómo una tecnología de género moderno colonial. Es decir, van a producir y administrar representaciones, roles, espacios, temporalidades e imaginarios sobre lo que significa ser una mujer con base en jerarquías de género, raza, clase y sexualidad. Además de formular un ideal de mujer emancipada implícito de atributos de blanquitud y occidentalidad, mientras construye la mujer problema, la rezagada, la atrasada en ese 
camino hacia la emancipación como alguien apegada a las costumbres, madre de más de tres hijos, analfabeta, sumergida en la pobreza y por supuesto no blanca.

Ahora bien, el dispositivo de desarrollo, ${ }^{6}$ y por ende las políticas públicas como tecnologías de género moderno colonial, están insertas en el tejido que despliegan los dispositivos homogeneizadores y diferenciadores que condensan las tensiones de un Estado y una sociedad pos independentista que proclama la igualdad de todos y todas, pero sin desprenderse de las jerarquías que estableció, y que sigue estableciendo, el legado colonial. A partir de los dispositivos homogeneizadores se entrelazan una serie de prácticas discursivas y no discursivas que van a subjetivar/engenerizar como mujeres a indias, negras y mestizas, proceso atravesado por los discursos y el accionar de las leyes, costumbres e instituciones racistas/clasistas que articulaban el dispositivo diferenciador. Pues bien, las políticas públicas de mujer y género recogen esta tensión, su corpus es como una bisagra en donde se pretenden homogeneizar muchas experiencias bajo la categoría mujer, al tiempo que hay una reescritura de la diferencia en la que se construyen los nuevos términos de la diferencia jerarquizante, cuyo punto de partida es la mayor o menor semejanza con la experiencia social y el proceso emancipatorio de las mujeres blancas. Lo que va a ocurrir es que una multiplicidad de experiencias va a ser reducida a la lógica binaría Mujer/ "mujer".

\section{DOS “MUJERES” Y UNA SOLA POLÍTICA PÚBLICA}

Las políticas públicas de equidad producen dos sujetos mujer, a las que llamaremos La Mujer y la "mujer", para este trabajo hemos seguido la propuesta de María Lugones (2008) de poner entre comillas a la que se le considera versión o símil. La primera es la original, la que usualmente es nombrada en singular y sin adjetivos, es el sujeto que condensa la experiencia femenina a plenitud, es la que mejor encarna el deber ser

${ }^{6}$ En un artículo titulado "Raza, pueblo y pobres: las tres estrategias biopolíticas del siglo XX en Colombia (1873-1962)”, Daniel Díaz (2008) explica que la raza, la educación y el desarrollo funcionaron de manera estratégica para "normalizar" a la población. Esta normalización consistía en producir binarios. "Normalizar la vida significaba binarizarla (normal/anormal) y cada estrategia biopolítica tuvo su propia normalización o binarización: la estrategia racial operó sobre la distinción útil/inútil; la estrategia educalizadora funcionó sobre la dicotomía culto/inculto y, por último, la gran estrategia del desarrollo inventó una nueva pareja maldita: desarrollo/subdesarrollo [...] se llegó a reducir toda la singularidad de la otredad bajo una imagen invertida de un Mismo despótico (p. 66). Y como explica este mismo autor, estas estrategias no funcionaron de manera separada u ordenada, sino que se superpusieron como capas, en donde es muy difícil saber dónde comienza una y termina la otra. 
de la norma de género, mientras que la segunda, la que casi siempre va acompañada de adjetivos como pobre, negra, indígena o campesina, es su versión fallida, la copia fracasada. Este juego dual de representaciones suele pasar desapercibido, sin embargo, para algunas feministas como Elsa Dorlin genera algunos cuestionamientos:

[...] cabría preguntarse si las técnicas discursivas dominantes "no organizarían" en cierta medida su propio fracaso. La dimensión performativa de las identidades sexuales, pero también sociales o de color, serían tanto más eficaces cuanto que no sólo hacen o no sólo fabrican nada más que sujetos dominantes. Todo transcurre como si ciertas performances fueran planteadas de entrada como originales, auténticas y reales, mientras que otras son paródicas e inauténticas, la relación de poder orquesta así una forma de ontologización de ciertas performances por un juego de imitaciones y copias más o menos conformes del sujeto real (Dorlin, 2009:102).

Esta manera de construir realidad es característica del discurso colonial y del discurso moderno colonial de género. El discurso colonial y sus dispositivos no sólo impusieron un régimen de saber/poder y de explotación económica sobre los pueblos colonizados, también impusieron un sistema de organización de la vida social basado en el dimorfismo sexual, que si bien, en un principio, durante la administración colonial, sólo normatizó la vida de los varones y las mujeres blancas, posteriormente, en las repúblicas pos independentistas va a ser adoptado como forma de organización de la vida social de todos los habitantes de las ex colonias. Se iba a producir, entonces, una engenerización de los cuerpos no blancos, sin embargo, esta engenerización al estar co-constituida con la jerarquía racial ${ }^{7}$ se volvía compleja y a nivel de roles, espacios e imaginarios respondía a criterios diferentes de los que contemplaba la norma de género para las personas blancas.

Dentro del aparato del poder colonial, los discursos de la sexualidad y la raza se relacionan con un proceso de sobredeterminación funcional, porque cada efecto [...] entra en resonancia o contradicción con los otros, y por ello exige un reajuste o una reelaboración de los elementos heterogéneos que suben a la superficie en distintos puntos (Bhabha, 1994:92).

\footnotetext{
7 "La construcción del sujeto colonial en el discurso, y el ejercicio del poder colonial a través del discurso, exigen una articulación de formas de diferencia, racial y sexual. Esa articulación se vuelve crucial si se sostiene que el cuerpo está siempre simultáneamente (aunque conflictivamente) inscripto tanto en la economía del placer y el deseo como en la economía del discurso, dominación y poder” (Bhabha, 1994:92).
} 
Por ejemplo, los imaginarios relacionados con la pasividad sexual de las mujeres o su debilidad física para el trabajo pesado son incompatibles con los creados alrededor de las negras e indígenas, vistas como lascivas sexualmente, impúdicas, o utilizadas como bestias de carga.

Las hembras no-blancas eran consideradas animales en el sentido profundo de ser seres "sin género", marcadas sexualmente como hembras, pero sin las características de la femineidad. Las hembras racializadas como seres inferiores pasaron de ser concebidas como animales a ser concebidas como símiles de mujer en tantas versiones de "mujer" como fueron necesarias para los procesos del capitalismo eurocentrado global (Lugones, 2008:94).

A pesar de las diferencias, a las dos se las llama mujeres y ello se debe a que nominar ${ }^{8}$ de la misma manera las experiencias y los relacionamientos afectivos de las personas negras e indígenas es parte de la estrategia de normalización de lo diferente, es una forma de imponer, regular y organizar los procesos de subjetivación, los relacionamientos sociales y afectivos, así como la distribución de trabajo y de los espacios. De esta manera todo queda contenido dentro de la matriz de comprensión del sistema moderno colonial de género.

Hay otro aspecto de las políticas públicas de equidad que permite esa producción de originales y copias y tiene que ver con el hecho de que están pensadas y diseñadas como políticas de identidad, lo que implica la construcción del sujeto de su reivindicación, de una categoría de sujeto (como se había mencionado arriba). Lo que resulta problemático es que ese sujeto mujer se basa única y exclusivamente en la experiencia de opresión de la mujer blanca, como ocurre con el sujeto del feminismo.

La lucha de las feministas blancas y de la "segunda liberación de la mujer" de los años 70 en adelante pasó a ser una lucha contra las posiciones, los roles, los estereotipos, los rasgos, y los deseos impuestos con la subordinación de las mujeres burguesas blancas.

${ }^{8}$ Sobre los efectos de la nominación o categorización Edward Said sostiene: "Algo patentemente extranjero y distante, adquiere por una razón u otra, un status más, y no menos familiar. Uno tiende, a dejar de juzgar las cosas como completamente novedosas u como completamente conocidas: emerge una nueva categoría intermedia, una categoría que le permite a uno ver cosas nuevas, cosas vistas por primera vez, como versiones de una cosa previamente conocida. En esencia esa categoría no es tanto un modo de recibir nueva información como un método de controlar lo que parece una amenaza a alguna visión establecida de las cosas [...] La amenaza es acallada, los valores conocidos se imponen, y al final la mente educe la presión acomodando las cosas ya como 'originales' ya como 'repetidas'” (Bhabha, 1994:100). 
No se ocuparon de la opresión de género de nadie más. Concibieron a "la mujer" como un ser corpóreo y evidentemente blanco, pero sin conciencia explícita de la modificación racial (Lugones, 2008:24).

Siguiendo a Lugones, la lógica categorial borra las diferencias al interior del grupo social mujer, mientras hace una homogeneización de las experiencias, ello impide observar la jerarquización, en donde el sector mujer dominante logra hacerse con la representación de todo el grupo. Si el sector que le da sentido al grupo mujer, es blanco, de clase media y heterosexual, eso significa que el resto: indígenas, negras, pobres, sean lesbianas o heterosexuales, sólo son capaces de una representación parcial o incompleta.

Esta lógica categorial hace parte de las operaciones binarias propias del pensamiento moderno colonial, en donde lo subalterno es pensado como lo otro al ser comparado y medido con los parámetros del sujeto normativo dominante que se erige en referente universal. Esta otredad está incompleta ontológicamente y por lo tanto deberá ser convertida, reducida a los términos del sujeto considerado universal.

De acuerdo con el patrón colonial moderno y binario, cualquier elemento, para alcanzar plenitud ontológica, plenitud de ser, deberá se ecualizado, es decir, conmensurabilizado a partir de una grilla de referencia o equivalente universal. Esto produce el efecto de que cualquier manifestación de la otredad constituirá un problema, y sólo dejará de hacerlo cuando sea tamizado por la grilla ecualizadora, neutralizadora de particularidades, de idiosincrasias (Segato, 2012:82).

En términos prácticos lo que se observa es que en las políticas públicas hay dos tipos de relato, uno contado en clave emancipatoria/feminista occidental con la descripción de la situación de la mujer, sus problemas y sus logros, apegado a la lógica categorial, y otro narrado sólo en forma de problema o excepción, siendo justamente este tipo de relato el que trae aparejada una explicación desde la diferencia, ya sea en términos de cultura y costumbres o de región, que en el caso de Colombia es una forma sutil de mencionar las diferencias raciales. Es importante resaltar que, en las políticas públicas de mujer y género, integradas al dispositivo del desarrollo, es la cuestión de la pobreza, la que se constituye en el relato de la excepción. Cuando se habla de pobreza se habla de mujeres oscuras limitadas por sus culturas opresoras "Para la bibliografía sobre el desarrollo [...] existe una verdadera subjetividad subdesarrollada dotada con rasgos como la impotencia, la pasividad, la pobreza y la ignorancia, por lo común de gente oscura y carente de protagonismo" (Escobar, 2007:28). 
Por ejemplo, en la Política de equidad y participación de las mujeres de 1994, puede leerse en uno de sus apartes ese relato en clave de liberación y "avance", incluso, se puede observar que el sustantivo mujer no está acompañado de ningún adjetivo.

La situación de la mujer ha mejorado significativamente durante los últimos cuarenta años. Su contribución al desarrollo nacional se ha hecho efectiva especialmente en tres campos: la educación, la transición demográfica y el mercado de trabajo (DNP, 1994:1).

Sin embargo, más adelante aparece el relato de la rezagada, en ese sí aparece el sustantivo mujeres acompańado por el adjetivo pobres.

La reducción de fecundidad no se ha dado de manera homogénea. Las mujeres pobres con menos educación continúan teniendo más hijos: en 1985, cuando la tasa nacional de fecundidad era de 3.2 niños por mujer en edad fértil, la de las mujeres no pobres era del 2.0, la de las pobres 3.7 y la de aquellas en situación de miseria 4.5 (DNP, 1994:3).

Estos relatos contrastados nos llevan hasta el concepto de mimesis ${ }^{9}$ que explica Bhabha y que es central en el discurso colonial. Como se ve, en las políticas públicas de mujer y género se construyen dos sujetos que aparecen confrontados en calidad de símiles/versiones frente a sus originales, pero el sujeto original encarna el modelo a seguir, mientras que el sujeto fallido, el que está en falta, es el impelido a parecerse lo mejor posible al sujeto original, en este caso, bajo la promesa de bienestar, de una mejor calidad de vida, de una vida libre de violencias, de emancipación y libertad. Entonces el efecto del juego de relatos es la continuidad de la occidentalización de ese sujeto fallido.

\section{DOS MUJERES, UNA SOLA LÍNEA DE TIEMPO}

Otro aspecto que resalta en el relato de las políticas públicas de equidad es el del tiempo y la ubicación de sus sujetos en él. En la narración, la "mujer" es presentada como viviendo en un tiempo pasado, entre prácticas arcaicas y tradiciones que deben ser transformadas desde afuera, ya que la percepción es de que se trata de seres inmóviles,

\footnotetext{
${ }^{9}$ El mimetismo colonial busca transformar al otro en un otro reconocible, para ello lo nomina con las categorías - mujer, varón, negro, indígena- que organiza el discurso colonial, sin embargo, ese otro siempre las desborda o está en falta. Y esa falta, falla o exceso será la diferencia que hará reconocible al sujeto colonial, siempre comparado con el sujeto original, socialmente presionado para lograr el mayor parecido posible pero siempre condenado a fallar.
} 
carentes de agencia. La Mujer en cambio es descrita como un sujeto en tiempo presente, que se ha ido transformando desde un pasado opresivo, y que se proyecta totalmente emancipada hacía el futuro, en este caso la imagen es la de un verdadero sujeto con agencia y capacidad de cambio. Parafraseando a Fanon, la narración convierte a la "mujer" en el pasado de la mujer blanca, y esta última se convierte en su futuro, en su devenir.

Tomemos un ejemplo bastante ilustrativo que se encontró en la Política integral de la mujer del año 1992, en uno de sus párrafos se puede observar como determinadas sociedades y ciertos modos de vida, en este caso los de los grupos sociales más pobres y de las regiones, que en Colombia se caracterizan por una gran presencia de población negra e indígena, son ubicadas arbitrariamente en el pasado. Estableciendo una correspondencia pasada/discriminación/cultura local necesaria para validar el relato futuro/emancipación/occidentalización como respuesta.

Todavía subsisten en ciertos estratos y regiones formas más arraigadas de discriminación contra la mujer basadas en patrones culturales del pasado. No obstante, dichos patrones siguen prevaleciendo en los sectores más pobres de la población (DNP, 1992:7).

La manera como en las políticas públicas de equidad se construye una línea del tiempo, una línea del proceso de emancipación de las mujeres está basada en la idea moderna de la no simultaneidad temporal (Fabian, 1983), esto implica que dos sociedades pueden coexistir en un mismo espacio, pero no en un mismo tiempo, porque sus modos de producción económica y cognitiva difieren en términos evolutivos. El modo de producción de riquezas (el capitalismo) y de conocimientos (la nueva ciencia) de la Europa Moderna es el criterio a partir del cual es posible medir el desarrollo temporal de todas las demás sociedades. El conocimiento habría pasado, entonces, por "diversos grados", medidos en una escala lineal, de la mentalidad primitiva al pensamiento abstracto, y lo mismo puede decirse de los modos de producción de riqueza, que progresan de la economía de subsistencia a la economía capitalista del mercado (Castro, 2010:36). Esta operación de sentido convierte otros mundos y otras sociedades en reductos del pasado europeo, una experiencia conocida y superada, negando su presente y por supuesto, su existencia.

Un ejercicio similar realiza el feminismo desarrollista, como ya lo ha manifestado la feminista india Chandra Mohanty, quien cuestiona al feminismo blanco occidental por representarse a sí mismo como la norma a seguir por parte de las mujeres del Tercer Mundo, al tiempo que representa a las otras, las del Tercer Mundo como pobres, analfabetas e inmaduras políticamente. 
Esta mujer promedio del tercer mundo lleva una vida esencialmente truncada debido a su género femenino (léase sexualmente constreñida) y su pertenencia al tercer mundo (léase ignorante, pobre, sin educación, limitada por las tradiciones, doméstica, restringida a la familia, víctima, etcétera). Esto, sugiero, contrasta con la autorepresentación (implícita) de la mujer occidental como educada, moderna, en control de su cuerpo y su sexualidad y con la libertad de tomar sus propias decisiones (Mohanty, 2008:5).

Ubicar a la "mujer" en el pasado recurriendo a un estereotipo basado en carencias, mientras se proyecta a la mujer blanca como presente y futuro promisorio en temas como educación, trabajo, libertad sexual y poder de decisión en todos los ámbitos de la vida social, evidencia un reordenamiento del tiempo propio de los discursos coloniales ${ }^{10}$, ya que ubica arbitrariamente a las negras, indias y mestizas como el pasado de la historia de la mujer blanca, ocultando procesos históricos locales coetáneos y pasando por encima de espacios geográficos y contextos culturales.

\section{LAS METÁFORAS GEOGRÁFICAS}

Pero no sólo se trata de la posición que se ocupa en la historia, única, lineal de la Mujer, también hay una reubicación espacial, un reacomodamiento arbitrario de las fronteras ${ }^{11}$ que crea un escenario de sentido para los sujetos que produce. Mientras la Mujer es descrita en situaciones que reflejan un contexto urbano, centro, la "mujer"

10 "La concepción moderna del tiempo construyó la alteridad mundial basada en una escala temporal, que ubicó a poblaciones y territorios en relación a lo nuevo o lo moderno. Esta concepción permitió construir el orden mundial por medio de procesos civilizatorios en diferentes épocas y de diferentes formas, pero siempre basado en el mismo patrón logocéntrico de medición A/no A, Civilizado/Bárbaro, Desarrollado/Subdesarrollado, Blanco/no Blanco. Acá es donde cobra sentido el tiempo como organizador mundial y es acá donde se crea la ilusión de la historia universal basada en procesos diferenciados, pero dentro de una misma línea de evolución” (Arévalo, 2009:4).

${ }^{11}$ Según Edward Said: "Podemos mantener que la mente crea algunos objetos distintivos que, aunque parecen existir objetivamente, sólo tienen una realidad ficticia. Un grupo que viva en unas cuantas hectáreas establecerá las fronteras entre su territorio, los inmediatamente colindantes y el territorio más alejado, al que llamará 'el territorio de los bárbaros'. En otras palabras, la práctica universal de establecer en la mente un espacio que es 'nuestro' y un espacio no familiar que es el suyo es una manera de hacer distinciones geográficas que pueden ser totalmente arbitrarias. Utilizo la palabra 'arbitrario' porque la geografía imaginaria que distingue entre 'nuestro territorio y el territorio de los bárbaros' no requiere que los bárbaros reconozcan esta distinción. A nosotros nos basta con establecer esas fronteras en nuestras mentes; así pues 'ellos' pasan a ser 'ellos' y tanto su territorio como su mentalidad son calificados como 
es relacionada con ámbitos periféricos, marginales o regionales, que evocan pobreza, migración y que insinúan la pertenencia a ciertos grupos raciales o tradiciones culturales, en el caso de la referencia a las regiones. Esta manera de situar a los sujetos, conlleva un reforzamiento de las jerarquías y las diferencias, tal y como lo hace el aparato del desarrollo cuando habla de un primer, segundo y tercer mundo o cuando utiliza la expresión norte/sur.

[De hecho] El discurso del desarrollo inevitablemente contiene una imaginación geopolítica que ha dominado el significado del desarrollo durante más de cuatro décadas. Para algunos autores, esta voluntad de poder espacial es uno de los rasgos esenciales del desarrollo (Slatter, 1993) y está implícita en expresiones tales como Primer y Tercer Mundo, Norte y Sur, Centro y Periferia. La producción social del espacio implícita en estos términos está ligada a la producción de diferencias, subjetividades y órdenes sociales (Escobar, 2007:29).

Este ejercicio de jerarquización también se da dentro de los espacios nacionales y locales, y se puede explicar a partir del concepto de colonialismo interno de Pablo González Casanova, según el cual las élites nacionales tienden a reproducir prácticas y estructuras coloniales que recrean una geografía de centros de poder y periferia al interior de los Estado-nación, que les permite organizar el control y la explotación de los territorios y las poblaciones, cabe señalar que esta distribución se fundamenta en diferencias de tipo racial. Esta operación espacial está integrada en la maquinaría binaria del pensamiento colonial, ya que la relación centro/periferia que se utiliza en las políticas públicas de equidad vuelve a poner en el centro las dicotomías: salvaje/ civilizado, blanco/no blanco, desarrollado/subdesarrollado, occidental/no occidental, pobreza/riqueza. Entonces, si organizamos la información lo que tendremos es que Mujer es igual a centro, civilización, blanco, riqueza, desarrollo, occidental, mientras que "mujer" se corresponde con salvaje, no blanco, subdesarrollo, no occidental, periferia, pobreza.

En estos dos fragmentos de la Política integral de 1992 se puede observar la construcción de esa geografía con centros de poder y periferia, que recrea un tercer mundo interno.

En áreas rurales $17 \%$ de los hogares tienen jefatura femenina, con problemas más agudos de pobreza que en las áreas urbanas (DNP, 1992:7).

diferentes de los nuestros [...] A las fronteras geográficas le siguen las sociales, étnicas y culturales de manera previsible" (Said, 2004:87). 
Las acciones y los recursos se concentran especialmente en la atención de las mujeres pobres de zonas rurales y urbanas marginales (DNP, 1992:7).

\section{HACER POLÍTICAS PÚBLICAS CON ESTEREOTIPOS}

Hasta aquí hemos visto cómo las políticas públicas de mujer y género producen dos sujetos mujer, y cómo cada una es ubicada en dimensiones diferenciadas de tiempo y espacio siguiendo la lógica de los dos relatos, uno contado en clave de emancipación y otro como problema/excepción. En el primer relato se construye un sujeto mujer tipo, para ello se destacan o se ponen en primer plano algunos rasgos que se consideran esenciales y que aparentemente permanecen en el tiempo "un tipo es cualquier caracterización sencilla, vivida, memorable, fácilmente interpretada y ampliamente reconocida en la que pocos rasgos son traídos al plano frontal y el cambio y el 'desarrollo' se mantienen en el mínimo" (Dyer, 1977:28). Además, los tipos sociales designan a aquellos que viven de acuerdo con las normas sociales.

El segundo relato apela a contar las experiencias de los sujetos fijándolos y limitándolos a una forma de estar y hacer, dando cuenta de una narración construida con estereotipos. Según Hall:

Los estereotipos retienen unas cuantas características "sencillas, vividas, memorables, fácilmente percibidas y ampliamente reconocidas" acerca de una persona, reducen todo acerca de una persona a esos rasgos, los exageran y simplifican y los fijan sin cambio o desarrollo hasta la eternidad. Este es el proceso que describimos anteriormente. Por consiguiente, el primer punto es: la estereotipación reduce, esencializa, naturaliza y fija la "diferencia" (2010:429).

Construir sujetos como estereotipos implica delineamientos planos; estabilidad en su descripción, esto quiere decir que siempre se les describe de la misma manera, en un proceso que privilegia la hipervisibilidad de ciertas características y el ocultamiento de otras; también hay un control o normalización de su diferencia mediante etiquetamientos de raza o género, así lo extraño es ubicado en una categoría conocida, manejable; los comportamiento y actitudes siempre tienen la misma explicación, incluso, para conductas totalmente opuestas: si trabajas mucho, trabajas como negro, si trabajas poco, eres perezoso como un negro. Por último, se encuentra la predictibilidad, que es la anticipación a sus posibles respuestas y acciones en determinadas situaciones. En resumen, hay una eliminación de la incertidumbre, bajo la premisa del "conocimiento 
profundo"12 de ese otro. Esto lo convierte en un ser objetivado, limitado, fijado a una idea sobre quién es. De manera definitiva se interrumpe la circulación de otras interpretaciones que posibiliten otros modos de ver, escuchar e imaginar al sujeto convertido en estereotipo. Como bien lo expresa Franz Fanon "Donde quiera que vaya, el Negro sigue siendo Negro" (2009).

Stuart Hall señala las que serían las principales diferencias entre un tipo y un estereotipo: el tipo fija la normalidad mientras que el estereotipo fija la diferencia. Es decir, mientras el tipo señala quienes encajan, quienes están dentro, el estereotipo señala quienes son los excluidos. Los estereotipos tienden a ser más cerrados y a fijar unos límites bien delineados, además de ser estables en el tiempo.

La estereotipación es, en otras palabras, parte del mantenimiento del orden social y simbólico. Establece una frontera simbólica entre lo "normal" y lo "desviante", lo "normal" y lo "patológico", lo "aceptable" y lo "inaceptable", lo que "pertenece" y lo que no pertenece o lo que es "Otro", entre "internos" y "externos", nosotros y ellos" (Hall, 2010:434).

Por último, la estereotipación tiende a ocurrir donde hay grandes desigualdades de poder, en donde un grupo tiene el poder suficiente para imponer un régimen de verdad, su visión del mundo, sus valores sobre cómo deben ser las personas y la sociedad, de ahí su preponderancia en el discurso colonial.

Pero, además, la imposición de un estereotipo sobre un "otro" implica la negación de su humanidad, en la medida en que no se le reconoce como sujeto agente con capacidad para razonar y tomar decisiones, tampoco se le reconoce un pasado, ni memoria. Esto pone de presente, otra vez, la dicotomía central de la modernidad colonial: lo humano y lo no humano, en donde lo humano era un atributo sólo de los blancos, y era además el prerrequisito para poder ser considerado varón o mujer (Lugones, 2010). La persistencia de prácticas discursivas que despojan de humanidad a ciertos grupos sociales, en el caso de estas políticas públicas a las indígenas, afros y mestizas empobrecidas, viene a reafirmar la larga duración del discurso de género moderno colonial y pone al descubierto quien es el verdadero sujeto mujer para el Estado, quien puede encarnar el tipo ideal Mujer y quien sólo puede aspirar a ser el estereotipo "mujer".

\footnotetext{
12 "Los sujetos del discurso son construidos dentro de un aparato de poder que contiene, en ambos sentidos de la palabra, un conocimiento 'otro', un conocimiento que está detenido y es fetichista, y circula a lo largo del discurso colonial como esa forma de otredad que he llamado estereotipo" (Bhabha, 1994:103).
} 
La reducción de un sujeto a estereotipo y el establecimiento de otro como tipo es el recurso discursivo que permite la coherencia interna de los dos relatos que contienen las políticas públicas de mujer y género, es lo que hace que sean relatos impermeables, eternamente paralelos y con unos sujetos plenamente diferenciados a pesar de estar cobijados por una misma nominación.

\section{REFLEXIÓN FINAL}

Las políticas públicas nacionales de mujer y género que se diseñaron y pusieron en marcha en Colombia durante la década de 1990-, articulan estratégicamente prácticas discursivas y no discursivas que permiten catalogarlas como tecnologías de género moderno colonial, es decir, que estas prácticas dan lugar a procesos de engenerización entretejidos con las jerarquías de raza, clase y sexualidad. Lo que se hace evidente en la forma como se construyen las representaciones del sujeto mujer, pero también en las acciones que integran los programas y proyectos que se formulan para solucionar el problema mujer.

Ahora bien, para comprender la importancia de las tecnologías de género moderno colonial es fundamental recordar que los procesos de subjetivación colonial no están acabados, continúan hasta hoy mediante estas políticas públicas que interpelan de manera constante al sujeto, ya que es mediante la repetición como se logra la materialización de la norma, en este caso, de una subjetividad fracturada por el deber ser de la norma de género blanca y los límites que impone la jerarquía racial, que son también los límites de la pirámide de clase. Las políticas públicas como tecnologías de género moderno colonial cumplen el papel que en algún momento cumplieron la encomienda, el derecho indiano y los manuales de urbanidad, y que hoy realizan los textos escolares, el derecho y las constituciones. Todas estas tecnologías se interconectaban o se interconectan siguiendo la lógica del campo de comprensión que organizan los dispositivos de homogeneización y diferenciación, que ordenan la vida social y el accionar del Estado mediante la imposición de categorías comunes y la jerarquización.

Vale decir que ese sujeto fracturado siempre intenta y desea encarnar al otro sujeto de la política, la mujer/blanca, aquella en donde se realiza plenamente la norma de género, es decir, en donde existe la coherencia entre el cuerpo, los roles, los espacios y los imaginarios. Y es que este deseo de ser la otra, ese deseo de occidentalización, es también la promesa de la emancipación para la "mujer", y así queda construido en los relatos especulares que corren paralelos en el texto de la política pública, que se 
materializará a partir de los proyectos y programas que se prescriben como solución para sus problemas.

Algo que queda en evidencia al revisar las políticas públicas es que la norma de género moderno colonial es dinámica y se transforma de acuerdo con los cambios geopolíticos que plantea la relación Norte/Sur, se podría decir que se actualiza. Al respecto debo señalar que en las tecnologías de género moderno colonial siempre hay procesos de recodificación de lo que significa ser una "mujer", esto implica muchas veces la exaltación de ciertos roles o la casi proscripción de otros; la revalorización de ciertos espacios, el cambio de actitud frente a ciertas tareas o la popularización de ciertos imaginarios. Ya advertía Lugones, que el sistema produce tantas versiones de mujer como sean necesarias para el funcionamiento del capitalismo global, y se pueden producir tantas porque las tensiones entre género, raza y clase que se agolpan bajo la imposición de la nominación mujer sobre los cuerpos colonizados borran las líneas de coherencia que sí existen en el sujeto mujer/blanca, el sujeto ontologizado. De esta manera, las formas de administrar las diferencias que producen los procesos de generización, de racialización y la clase social se presentan infinitas así sean esquizofrénicas, contradictorias y dolorosas, lo importante es producir las "mujeres" que necesita el proceso de explotación colonial capitalista.

\section{REFERENCIAS}

Arévalo, Andrés (2009). "La configuración temporal del orden mundial: una mirada moderna/ colonial”, Trabajos y ensayos, núm. 9, pp. 1-20.

Bhabha, Homi (1994). El lugar de la cultura. Buenos Aires: ediciones Manantial.

- (2002). El lugar de la cultura. Buenos Aires: Ediciones Manantial.

Butler, Judith (2002). Cuerpos que importan. Madrid: Editorial Paidós.

Castro Gómez, Santiago (2010). La hybris del punto cero. Bogotá, Colombia: Pontificia Universidad Javeriana.

Davis, Angelae (2005). Mujer, raza y clase. Madrid: Akal.

De Lauretis, Teresa (2000). Diferencias. Madrid: Horas y Horas.

Departamento Nacional de Planeación (1992). "Política integral para la mujer". - (1994). "Política de equidad y participación de las mujeres".

Departamento Nacional de Planeación (1997). "Avance y ajustes de la política de participación y equidad para las mujeres".

Díaz, Daniel (2008). "Raza, pueblo y pobres: las tres estrategias biopolíticas del siglo XX en Colombia (1873-1962)”, en Santiago Castro-Gómez y Eduardo Restrepo (eds.), Genealogías de la colombianidad. Bogotá, Colombia: Universidad Javeriana, pp. 42-70.

Dorlin, Elsa (2009). Sexo, género y sexualidades. Buenos Aires: Ediciones Nueva Visión.

Dyer, Richard (1977). Gays and film. Londres, British film Institute. 
Edouard, Glissant (2010). El discurso antillano. La Habana: Casa de las Américas.

Escobar, Arturo (2007). La invención del Tercer Mundo. Caracas: Fundación Editorial El Perro y la Rana.

Fabian, Johannes (1983). Time and the other. Nueva York: Columbia University Press.

Fanon, Franz (2009). Piel negra mascaras blancas. Madrid: Akal.

Hall, Stuart (2010). Sin garantías. Popayán, Colombia: Envión Editores.

Lugones, María (2008). "Colonialidad y género", Tabula Rasa (9). pp. 73-101.

Lugones, María (2010). "Hacía un feminismo descolonial”, La Manzana de la Discordia, 6(2). pp. 105-119.

Mohanty, Chandra (2008). "Bajo los ojos de occidente. Academia feminista y discurso colonial", en L. Suarez y R. Hernández (eds.), Descolonizando el feminismo: teorías y prácticas desde los márgenes. Madrid: Cátedra, pp. 112-160.

Moreno, Hortensia (2011). "La noción de 'tecnologías de género' como herramienta conceptual en el estudio del deporte, Revista Punto Género, núm. 1, pp. 41-62.

Mueller, Adele (1987). "Power and naming in the development institution, the 'Discovery' of 'women in Peru'", 14th Annual Third World Conference, Chicago.

Muller, Pierre (2006). Las politicas públicas. Bogotá: Universidad Externado de Colombia.

Puello José Francisco (2007). "La dimensión cognitiva en las políticas públicas. Interpelación politológica”, Ciencia Política, núm. 3, pp. 36-57. Rivera, Silvia (2010). Violencias (re) encubiertas en Bolivia. La Paz: La Mirada Salvaje.

Said, Edward (2004). Orientalismo. Barcelona: Debolsillo.

Segato, Rita (2012). "Colonialidad y patriarcado moderno: expansión del frente estatal, modernización y la vida de las mujeres", en Yuderkys Espinosa et al. (eds.), Tejiendo de otro modo: feminismo, epistemología y apuestas decoloniales en Abya Yala. Popayán, Colombia: Editorial Universidad del Cauca, pp. 75-90. 


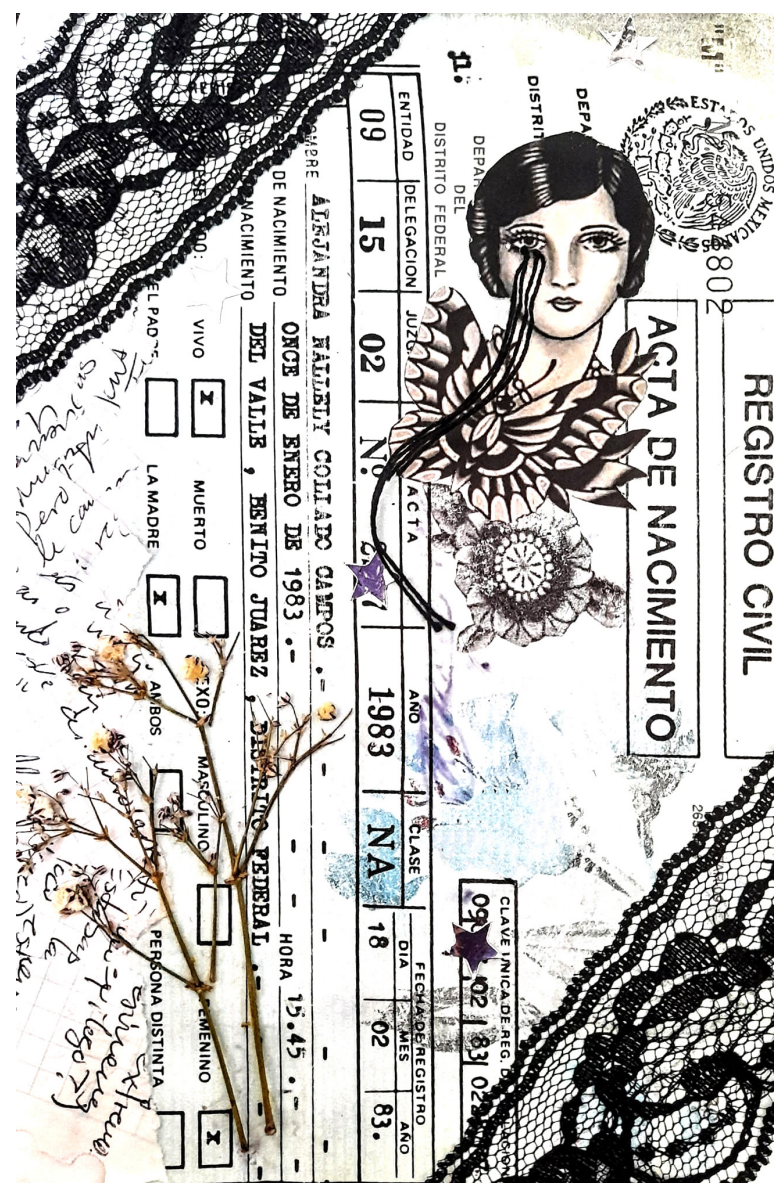

Nacida viva en el Distrito Federal de los años 80 . Abrí los ojos por la tarde. 
Alejandra Collado | Documento de identidad

Bordado y estampado sobre collage de papel

Mayo de 2021 